\title{
Anemia Is a Predictive Factor for Overall Survival Rate in Patients With Non- small Cell Lung Cancer Treated With Stereotactic Body Radiation Therapy
}

Hidekazu Tanaka ( $\square$ h-tanaka@yamaguchi-u.ac.jp)

Gifu University https://orcid.org/0000-0002-8673-5707

Taiki Ono

Yamaguchi University School of Medicine Graduate School of Medicine: Yamaguchi Daigaku Igakubu Daigakuin Igakukei Kenkyuka Yuki Manabe

Yamaguchi University School of Medicine Graduate School of Medicine: Yamaguchi Daigaku Igakubu Daigakuin Igakukei Kenkyuka Miki Kajima

Yamaguchi University School of Medicine Graduate School of Medicine: Yamaguchi Daigaku Igakubu Daigakuin Igakukei Kenkyuka Koya Fujimoto

Yamaguchi University School of Medicine Graduate School of Medicine: Yamaguchi Daigaku Igakubu Daigakuin Igakukei Kenkyuka Yuki Yuasa

Yamaguchi University School of Medicine Graduate School of Medicine: Yamaguchi Daigaku Igakubu Daigakuin Igakukei Kenkyuka Takehiro Shiinoki

Yamaguchi University School of Medicine Graduate School of Medicine: Yamaguchi Daigaku Igakubu Daigakuin Igakukei Kenkyuka Yoshikazu Yamaji

Yamaguchi University School of Medicine Graduate School of Medicine: Yamaguchi Daigaku Igakubu Daigakuin Igakukei Kenkyuka Kazuto Matsunaga

Yamaguchi University School of Medicine Graduate School of Medicine: Yamaguchi Daigaku Igakubu Daigakuin Igakukei Kenkyuka

\section{Research}

Keywords: Anemia, hemoglobin, non-small cell lung cancer, stereotactic body radiation therapy, stereotactic ablative body radiotherapy

Posted Date: August 9th, 2021

DOI: https://doi.org/10.21203/rs.3.rs-770158/v1

License: (c) (1) This work is licensed under a Creative Commons Attribution 4.0 International License. Read Full License 


\section{Abstract}

Purpose: Anemia has been associated with poor prognosis in patients with cancer across several cancer types. It has been identified as a prognostic factor in patients with non-small cell lung cancer (NSCLC) who have undergone surgery or chemoradiotherapy. However, there are only a few reports that have evaluated the prognostic significance of anemia in patients with NSCLC undergoing stereotactic body radiation therapy (SBRT).

Material and Methods: A total of 77 patients were enrolled this study. The pretreatment hemoglobin (Hb) levels, within 2 weeks before SBRT, were available for all patients. The median age of the participants (56 men, 21 women) was 80 (range, 50-90) years. The median $\mathrm{Hb}$ level was 12.8 (range, 7.8-18.3) g/dL. The median follow-up period was 24 (range, 1-87) months.

Results: Local recurrence was observed in 8 (10.4\%) cases during the follow-up period. The 1- and 2-year local control (LC) rates were 94.8 and $86.4 \%$, respectively. Seventeen (22.1\%) patients died during the follow-up period. The 1 - and 2-year overall survival (OS) rates were 93.1 and $85.2 \%$, respectively. Univariate analysis identified anemia and body mass index as significant prognostic factors for predicting OS. On multivariate analysis, anemia was confirmed to be the only significant factor $(p=0.02469)$.

Conclusion: Our data suggest that anemia is a prognostic factor for predicting the OS rate in patients with early-stage NSCLC treated with SBRT.

\section{Introduction}

Among all cancers, lung cancer had the highest estimated incidence and mortality rates in 2018 worldwide [1]. An estimated 2,094,000 people worldwide were diagnosed with lung cancer in 2018, resulting in 1,761,000 deaths. Stereotactic body radiation therapy (SBRT) is an important treatment option for early-stage non-small cell lung cancer (NSCLC) with results comparable to surgery [2]. Nagata Y et al. reported favorable outcomes in both operable and inoperable NSCLC cases treated by SBRT [3]. Chang JY et al. reported good results of SBRT in a pooled analysis of patients enrolled in two phase-III trials that compared surgery with SBRT [4].

Anemia has been associated with a poor prognosis in patients with cancer across various types of cancer [5-10]. In patients with NSCLC who undergo surgery [11-13] or radiation therapy or chemoradiotherapy [14-17], anemia has been reported as a poor prognostic factor. However, there is limited literature available on the prognostic significance of anemia in patients with NSCLC undergoing SBRT. The purpose of this study was to evaluate the association between pretreatment anemia and prognosis in patients with NSCLC treated with SBRT.

\section{Methods And Materials}

\section{Patients}

This retrospective study was conducted with the approval of our institutional review board, and all patients provided written informed consent before treatment. The inclusion criteria were as follows: patients with localized NSCLC, NOMO disease, who were clinically inoperable or refused surgery, and were treated with SBRT, and for whom the hemoglobin ( $\mathrm{Hb}$ ) levels were available within 2 weeks before SBRT. Between September 2009 and September 2019,77 patients meeting the inclusion criteria were identified and included in the study. Cases where the pathological diagnosis could not be confirmed were treated as NSCLC if the joint conference of respiratory surgeons, pulmonologists, radiologists, and radiation oncologists came to that consensus.

\section{Planning and irradiation}

Before radiation treatment planning, patients were evaluated by four-dimensional computed tomography (4DCT) using Somatom (SIEMENS, Germany) for the amount of movement of the tumor caused by respiration. For 4DCT, real-time positioning management (RPM) system (Varian Medical Systems, USA) was used. Patients with respiratory motion of the tumor $\geq 1.0 \mathrm{~cm}$ were planned for the implantation of a fiducial marker which were implanted by bronchoscopy near the tumor. For every such patient, three markers were implanted.

All patients underwent the CT scan under light exhalation breath-hold, and 4DCT were also performed using RPM. The slice thickness was 1.0 or 2.0 mm. Patients were immobilized using Vac-Loc Cushion (CIVCO Medical Solution, USA) with both their arms up. The clinical target volume (CTV) was defined as equal to the gross tumor volume (GTV). In patients with implanted fiducial markers, the internal target volume (ITV) was equal to the CTV. In contrast, summation of the GTVs defined at every respiratory phase of the 4DCT gave the ITV in patients without the fiducial marker. The planning target volume (PTV) was generated by adding $5 \mathrm{~mm}$ around the ITV. In principle, the prescribed dose for peripherally situated tumors was 50 Gy in 5 fractions until September 2016 and $48 \mathrm{~Gy}$ in 4 fractions after October 2016. The tumors with a central location near organs at risk were treated with $60 \mathrm{~Gy}$ in 8 fractions. A central tumor was defined as a tumor whose distance from the proximal bronchial tree was $\leq 2 \mathrm{~cm}$. The dose was prescribed to the isocenter. Leaf margins were modified to cover the PTV by $80 \%$ of the prescribed dose. The linear accelerator used was MHCL-15DP (Mitsubishi Electronics, Japan) until September 2015, and TrueBeam (Varina Medical Systems, USA) after October 2015. Treatment planning used of 6-8 beams, including 4-6 non-coplanar beams.

The treatment for patients with implanted fiducial markers was performed under motion tracking using a real-time tumor tracking system (Mitsubishi Electronics, Japan) until September 2015 and SyncTraX (Shimadzu Corporation, Japan) after October 2015. In brief, the system consists of two sets of X-ray tubes under the floor and image intensifiers on the ceiling. The fiducial marker implanted near the tumor is easily visible on the radiograph and is tracked in real time. The position of the marker is recognized as a surrogate of the tumor position. The treatment beam turns on only when the marker is located within designated area. The detailed method has been described in literature earlier [18].

The treatment for patients without fiducial marker was performed under light free breathing. 


\section{Evaluation}

The medical charts were reviewed and data pertaining to age, sex, performance status (PS), body mass index (BMI), operability, smoking history (current or past vs. never smoker), the presence of diabetes mellitus (DM), the presence of pathological or cytological confirmation, tumor diameter, irradiation method (respiratory gated or not), and pretreatment $\mathrm{Hb}$ levels were obtained.

The World health organization defines $\mathrm{BMI}<18.5$ as underweight [19] Base on the BMI $\left(\mathrm{kg} / \mathrm{m}^{2}\right)$ (calculated as follow: body weight $(\mathrm{kg}) /[$ height ( $\left.\left.\mathrm{m})\right]^{2}\right)$, the patients were classified into two groups (BMI $<18.5$ and $\geq 18.5)$.

The survival periods were calculated from the completion of the SBRT.

The associations between $\mathrm{Hb}$ levels and other categorical variables were tested using Mann-Whitney $\mathrm{U}$ test and the correlation with continuous variables was tested by Spearman's rank correlation coefficient. Local control (LC) and overall survival (OS) rates were calculated using the Kaplan-Meier method, and group comparisons were made using the log-rank test. Univariate and multivariate Cox proportional hazard regression models were used to estimate the LC and OS rates. Variables for which the $p$-values were $<0.10$ in the univariate analysis were included in the multivariate analysis. Receiver-operating characteristic (ROC) analysis was performed to determine the optimal cut-off values for the pretreatment $\mathrm{Hb}$ level. A p-value $<0.05 \mathrm{was}$ considered to indicate a statistically significant difference.

\section{Results}

The patient characteristics are shown in Table 1. The median age of the 77 participants (56 men, 21 women) was 80 (range, 50-90) years. Most of the patients presented with a PS of 0 or $1(n=71,92.2 \%)$. The median BMI was 21.5 (range, $13.1-37.3) \mathrm{kg} / \mathrm{m}^{2}$. The median diameter of the tumor was 19 (range, $7-40) \mathrm{mm}$. More than half of the patients had a history of smoking $(n=57,74.0 \%)$. The number of patients with a pathological confirmation of the diagnosis of NSCLC was $35(45.4 \%)$. The numbers of patients with diabetes was $17(22.1 \%)$. The reason for choosing SBRT was either inoperability $(n=56,72.7 \%)$ or refusal of surgery $(n=21,27.3 \%)$. The median $\mathrm{Hb}$ level was 12.8 (range, $7.8-18.3) \mathrm{g} / \mathrm{dL}$.

The association between $\mathrm{Hb}$ levels and other parameters are shown in Table 2. The Hb levels were significantly lower in patients with lower BMI than in patients with a higher BMI. There was a weak positive correlation between $\mathrm{Hb}$ level and BMI. Also, the Hb levels were significantly higher in patients with a smoking history than in those without a smoking history. There was no significant correlation observed between $\mathrm{Hb}$ levels and the other parameters.

\section{Outcome}

The median follow-up period was 24 (range, 1-87) months. Local recurrence was observed in 8 (10.4\%) cases during the follow-up period. The 1- and 2-year LC rates were 94.8 and $86.4 \%$, respectively. In univariate analysis, there was no significant prognostic value of the LC rate (Table 3 ).

Seventeen (22.1\%) patients died during the follow-up period with 7 of them dying from lung cancer. The 1-and 2-year OS rates were 93.1 and $85.2 \%$, respectively. Univariate analysis found anemia and BMI as significant factors for predicting the OS rates. Multivariate analysis confirmed anemia as the only significant independent prognostic factor $(p=0.02469)$ (Table 4). The optimal cut-off values of Hb level, as determined by ROC analysis, was $11.6 \mathrm{~g} / \mathrm{dL}$. The OS rates with lower $\mathrm{Hb}$ level was significantly poor that that with higher $\mathrm{Hb}$ level $(\mathrm{p}=0.00767)($ Fig. 1$)$. The 1-and 2-year OS rates for higher and lower $\mathrm{Hb}$ groups were $96.1 \%$ and $88.3 \%$, and $84.4 \%$ and $76.0 \%$, respectively.

\section{Discussion}

There was a weak positive correlation between $\mathrm{Hb}$ level and BMI. $\mathrm{Hb}$ levels in patients with lower BMI were significantly lower than in the group with higher $\mathrm{BMI}$. This is explained by the fact that $\mathrm{Hb}$ level is correlated with nutritional status. That is, patients with poor nutrition had low $\mathrm{Hb}$ levels and low $\mathrm{BMI}$. $\mathrm{Hb}$ levels were significantly higher in patients with smoking history than in those without smoking history. This was because most smokers were men. In fact, men (92.5\%) had a significantly higher smoking history than women (40.0\%) (Fisher's exact test, $p=0.00000735$ ). Median pretreatment $\mathrm{Hb}$ levels in men and women were 13.1 (range, 8.9-18.3) and 11.4 (range, 7.8-14.6), respectively. Because men had significantly higher $\mathrm{Hb}$ levels than women ( $p=0.0187$ ), and most smokers were men, smoking history could not be directly correlated with elevation of Hb levels.

In the recent years, there have been many reports indicating that pretreatment $\mathrm{Hb}$ levels significantly correlates with the outcomes in several types of cancer [5-10]. These reports include various treatment modalities, such as surgery, chemotherapy, radiation therapy, and combination of them. Though various outcome measures were reported the OS rates were most commonly reported. In patients with NSCLC, pretreatment Hb level was a significant predictor of prognosis in patients with treated by surgery or chemoradiotherapy [11-17]. However, literature about correlation between anemia and outcome in patients of NSCLC undergoing SBRT is lacking. To the best of our knowledge, the report by Shaverdian N et al, is an only report on the given subject [20]. They reported that pretreatment $\mathrm{Hb}$ levels correlated significantly with OS rate and non-local disease progression, but not with LC rate. Their results were comparable to our results, where we found pretreatment $\mathrm{Hb}$ levels to correlate significantly with OS rate but not with the LC rate.

Anemia is considered to cause of intratumor hypoxia [21]. Because tumor hypoxia is one of the causes of radioresistance, patients with anemia are expected to have a lower LC rate post radiation therapy. However, in our results, pretreatment Hb levels correlated significantly with OS rate but not with the LC rate. There are a few hypotheses to explain this result. Hypoxia inducible factor (HIF) was discovered from hepatocellular carcinoma cell lines as a factor that could induce hypoxia dependent erythropoietin [22]. HIF-1 induced the vascular endothelial growth factor, platelet-derived growth factor B, and basic fibroblast growth factor, and improved hypoxia [23]. In tumors, HIF-1 gets activated in response to hypoxia [24]. Therefore, it cannot be concluded that the oxygen concentration in the tumor of patients with a low serum $\mathrm{Hb}$ level will be lower than that of patients with a high serum $\mathrm{Hb}$ level. Additionally, $\mathrm{HIF}$ causes 
epithelial-mesenchymal transition and also promotes metastasis [25]. Hypoxia promotes tumor growth and progression to more aggressive character due to neo-angiogenesis, gene mutation, apoptosis inhibition, and free radical generation [21, 26-28].

SBRT is a relatively new treatment method. Many prognostic factors have been recently reported in patients with NSCLC who undergo SBRT, such as tumor size and standardized uptake value on 18F-fluorodeoxyglucose positron emission tomography [29, 30]. Pretreatment $\mathrm{Hb}$ level is an easily derived and cost effective blood parameter. Therefore, the utility of pretreatment $\mathrm{Hb}$ as a predictive prognostic indicator is high in the clinical setting.

\section{Conclusion}

Our data suggests that anemia is correlated with OS rates in patients with early-stage NSCLC who are treated with SBRT.

\section{Abbreviations}

SBRT; stereotactic body radiation therapy, NSCLC; non-small cell lung cancer, Hb; hemoglobin, 4DCT; four-dimensional computed tomography, CTV; clinical target volume, GTV; gross tumor volume, ITV; internal target volume, PTV; planning target volume, PS; performance status, BMI; body mass index, DM; diabetes mellitus, LC; local control, OS; overall survival, ROC; receiver-operating characteristic, HIF; hypoxia inducible factor.

\section{Declarations}

\section{Ethical approval and Consent to participate}

This retrospective chart review study involving human participants was in accordance with the ethical standards of the institutional and national research committee and with the 1964 Helsinki Declaration and its later amendments or comparable ethical standards. The Human Investigation Committee (IRB) of Yamaguchi University approved this study (H2019-101).

\section{Consent for publication}

Not applicable

\section{Availability for supporting data}

The datasets used and analyzed during the current study are available from the corresponding author on reasonable request.

\section{Competing interests}

The authors declare that they have no competing interests.

\section{Funding}

The authors did not receive support from any organization for the submitted work.

\section{Author's contribution}

Conceived and designed the experiments: HT, TS, YYam, KM. Wrote the first draft of the manuscript: HT. Contributed to the writing of the manuscript: HT, TO, YM, MK, KF, YYua, TS, YYam, KM. Agree with manuscript results and conclusions: HT, TO, YM, MK, KF, YYua, TS, YYam, KM. Jointly developed the structure and arguments for the paper: HT, TS, KM. Made critical revisions and approved final version: HT, TO, YM, MK, KF, YYua, TS, YYam, KM. All authors reviewed and approved the final manuscript.

\section{Acknowledgements}

Not applicable

\section{References}

1. GLOBOCAN 2018 [homepage on internet]. Lyon, France: International Agency for Research on Cancer, World Health Organization. [updated 2018 Sep: cited 2020 Oct 22]. Available from http://gco.iarc.fr/today/onlineanalysis-multi-bars?v=2018\&mode=cancer\&mode_population $=$ countries\&population=900\&populations=900\&key=asr\&sex=2\&cancer=39\&type=0\&statistic=5\&prevalence=0\&population_group=0\&ages_group $\% 5 \mathrm{~B} \% 5 \mathrm{D}$

2. NCCN Guidelinesfor treatment of cancer by site. Non-Small cell lung cancer. 2020 [homepage on internet]. Pennsylvania, US: National Comprehensive Cancer Network. [updated 2020 May 21: cited 2020 Oct 22]. Available from https://www.nccn.org/professionals/physician_gls/pdf/nscl.pdf

3. Nagata Y, Hiraoka M, Shibata T, Onishi H, Kokubo M, Karasawa K, et al. Prospective trial of stereotactic body radiation therapy for both operable and inoperable T1NOMO non-small cell lung cancer: Japan Clinical Oncology Group study JC0G0403. Int J Radiat Oncol Biol Phys. 2015; 93: 989-96.

4. Chang JY, Senan S, Paul MA, Mehran RJ, Louie AV, Balter P, et al. Stereotactic ablative radiotherapy versus lobectomy for operable stage I non-small-cell lung cancer: a pooled analysis of two randomized trial. Lancet Oncol 2015: 16: 630-7.

5. Dubsky P, Sevelda P, Jakesz R, Hausmaninger H, Samonigg H, Seifert M, et al. Anemia is a significant prognostic factor in local relapse-free survival of premenopausal breast cancer patients receiving adjuvant Cyclophosphamide/Methotrexate/5-Fluorouracil chemotherapy. Clin Cancer Res. 2008; 14: 
2082-7.

6. Koulis TA, Kornaga EN, Banerjee R, Phan T, Ghatage P, Magliocco AM, et al. Anemia, leukocytosis and thrombocytosis as prognostic factor in patients with cervical cancer treated with radical chemoradiotherapy: a retrospective cohort study. Clin Transl Radiat Oncol. 2017; 4: 51-6.

7. Guo SS, Tang LQ, Chen QY, Zhang L, Liu LT, Huang PY, et al. Is hemoglobin level in patients with nasopharyngeal carcinoma still a significant prognostic factor in the era of intensity-modulated radiotherapy technology? PLoS One. 2015; 10: e0136033.

8. Väyrynen JP, Tuomist A, Väyrynen SA, Klintrup K, Karhu T, Mäkelä J, et al. Preoperative anemia in colorectal cancer: relationships with tumor characteristics, systemic inflammation, and survival. Sci Rep. 2018; 8: 1126.

9. Huang XZ, Yang YC, Chen Y, Wu CC, Lin RF, Wang ZN, et al. Preoperative anemia or low hemoglobin predicts poor prognosis in gastric cancer patients: a meta-analysis. Dis Markers. 2019; 7606128.

10. Laurie SA, Jeyabalan N, Nicholas G, MacRae R, Dahrouge S. Association between anemia arising during therapy and outcomes of chemoradiation for limited small-cell lung cancer. J Thorac Oncol. 2006; 1: 146-51.

11. Yovino S, Kwok Y, Krasna M, Bangalore M, Suntharalingam M. An association between preoperative anemia and decreased survival in early-stage nonsmall-cell lung cancer patients treated with surgery alone. Int J Radiat Oncol Biol Phys. 2005; 62: 1438-43.

12. Jazieh AR, Hussain M, Howington JA, Spencer HJ, Husain M, Grismer T, et al. Prognostic factors in patients with surgically resected stage I and II nonsmall cell lung cancer. Ann Thorac Surg. 2000; 70: 1168-71.

13. Chamogeorgakis T, Anagnostopoulos C, Kostopanagiotou G, Bhora F, Toumpoulis I, Georgiannakis E, et al. Does anemia affect outcome after lobectomy or pneumonectomy in early stage lung cancer patients who have not received neo-adjuvant treatment. Thorac Cardiovasc Surg. 2008 ; 56: $148-53$.

14. Holgersson G, Sandelin M, Hoye E, Bergström S, Henriksson R, Ekman S, et al. Swedish lung cancer radiation study group: the prospective value of anemia, thrombocytosis and leukocytosis at time of diagnosis in patients with non-small cell lung cancer. Med Oncol. $2012 ; 29: 3176-82$.

15. Langendijk $\mathrm{H}$, de Jong J, Wanders R, Lambin P, Slotman B. The importance pre-treatment haemoglobin level in operable non-small cell lung carcinoma treated with radical radiotherapy. Radiother Oncol. 2003; 67: 321-5.

16. Pradier $\mathrm{O}$, Lederer $\mathrm{K}$, Hille A, Weiss $\mathrm{E}$, Christiansen $\mathrm{H}$, Scmidberger $\mathrm{H}$, et al. Concurrent low-dose cisplatin and thoracic radiotherapy in patients with in operable stage III non-small cell lung cancer: a phase II trial with special reference to the hemoglobin level as prognostic parameter. J Cancer Res Clin Oncol. 2005; 131: 261-9.

17. Topkan E, Selek U, Ozdemir Y, Yildirim B, Guler OC, Mertsoylu H, et al. Chemoradiotherapy-induced hemoglobin nadir values and survival in patients with stage III non-small cell lung cancer. Lung Cancer. 2018; 121: 30-6.

18. Hanazawa H, Takahashi S, Shiinoki T, Park SC, Yuasa Y, Koike M, et al. Clinical assessment of coiled fiducial markers as internal surrogates for hepatocellular carcinomas during gated stereotactic body radiotherapy with a real-time tumor-tracking system. Radiother Oncol. 2017; 123: 43-8.

19. Body mass index - BMI [homepage on internet]. Copenhagen, Denmark: World Health Organization Regional Office for Europe. [updated 2020 Oct 13 : cited 2020 Oct 22]. Available from https://www.euro.who.int/en/health-topics/disease-prevention/nutrition/a-healthy-lifestyle/body-mass-index-bmi

20. Shaverdian N, Veruttipong D, Wang J, Kupelian P, Steinberg M, Lee P. Pretreatment anemia portends poor survival and nonlocal disease progression in patients with stage I non-small cell lung cancer treated with stereotactic body radiation therapy. J Thorac Oncol. 2016; 11: 1319-25.

21. Harrison LB, Chadha M, Hill RJ, Hu K, Shasha D. Impact of tumor hypoxia and anemia on radiation therapy outcomes. Oncologist. 2002; 7: $492-508$.

22. Semenza GL, Wang GL. A nuclear factor induced by hypoxia via de novo protein synthesis binds to the human erythropoietin gene enhancer at a site required for transcriptional activation. Mol Cell Biol. 1992; 12: 5447-54.

23. Rey S, Semenza GL. Hypoxia-inducible factor-1-dependent mechanism of vascularization and vascular remodeling. Cardiovasc Res. 2010 ; $86: 236-42$.

24. Brown JM, Wilson WR. Exploiting tumour hypoxia in cancer treatment. Nat Rev Cancer. 2004; 4: 437-7.

25. Jiang J, Tang YL, Liang XH. EMT: a new vision of hypoxia promoting cancer progression. Cancer Biol Ther. 2011; 11: 714-23.

26. Varlotto J, Stevenson MA. Anemia, tumor hypoxia, and the cancer patient. Int J Radiat Oncol Biol Phys. 2005; 63: 25-36.

27. Coquelle A, Toledo F, Stern S Bieth A, Debatisse M. A new role for hypoxia in tumor progression: induction of fragile site triggering genomic rearrangements and formation of complex DMs and HSRs. Mol Cell. 1998; 2: 259-65.

28. Dachs GU, Tozer GM. Hypoxia modulated gene expression: angiogenesis, metastasis and therapeutic exploitation. Eur J Cancer. 2000; 36: 1649-60.

29. Matsuo Y, Shibuya K, Nagata Y, Takayama K, Norihisa Y, Mizowaki T, et al. Prognostic factors in stereotactic body radiotherapy for non-small- cell lung cancer. Int J Radiat Oncol Biol Phys. 2011; 79: 1104-11.

30. Tanaka H, Hayashi S, Hoshi H. Pretreatment maximum standardized uptake value on 18F-fluorodeoxyglucose positron emission tomography is a predictor of outcome for stage I non-small cell lung cancer after stereotactic body radiotherapy. Asia Pac J Clin Oncol. 2016; 12 : e113-7.

\section{Tables}


Table 1

Patients characteristics $(\mathrm{N}=77)$

\begin{tabular}{|c|c|}
\hline Parameters & median (range) \\
\hline Age (yraes) & $80(50-90)$ \\
\hline Sex (male/ female) & $56(72.7 \%) / 21(27.3 \%)$ \\
\hline PS $(0 / 1 / 2 / 3)$ & $41(53.2 \%) / 30(39.0 \%) / 5(6.5 \%) / 3(3.9 \%)$ \\
\hline BMI $\left(\mathrm{kg} / \mathrm{m}^{2}\right)$ & $21.5(13.1-37.3)$ \\
\hline$(<18.5 / \geq 18.5)$ & $23(29.9 \%) / 54(70.1 \%)$ \\
\hline Operability (yes / no) & $21(27.3 \%) / 51(66.2 \%)$ \\
\hline Smoking history (yes / no) & $57(74.0 \%) / 20(26.0 \%)$ \\
\hline DM (yes / no) & $17(22.1 \%) / 30(39.0 \%)$ \\
\hline Pathology (confirmed / unkown) & $35(45.5 \%) / 42(54.5 \%)$ \\
\hline Tumor diameter (mm) & $19(7-40)$ \\
\hline Irradiatiion (gating / non-gating) & $58(75.3 \%) / 19(24.7 \%)$ \\
\hline Pretreatment $\mathrm{Hb}(\mathrm{g} / \mathrm{dL})$ & $12.8(7.8-18.3)$ \\
\hline \multicolumn{2}{|l|}{ Prescribed dose } \\
\hline $48 \mathrm{~Gy}$ in 4 fractions & $50(64.9 \%)$ \\
\hline 50 Gy in 5 fractions & $23(29.9 \%)$ \\
\hline 60 Gy in 8 fractions & $4(5.2 \%)$ \\
\hline Follow-up periods (months) & $24(1-87)$ \\
\hline
\end{tabular}

Table 2

Association between $\mathrm{Hb}$ and other parameters

\begin{tabular}{|c|c|c|c|}
\hline \multicolumn{2}{|l|}{ Categorical variables } & \multicolumn{2}{|l|}{$p$-value } \\
\hline & Age (<80 vs. $\geq 80)$ (years) & 0.363 & \\
\hline & Sex (male vs. female) & 0.0187 & \\
\hline & PS (0 vs. $\geq 1)$ & 0.527 & \\
\hline & BMI (<18.5 vs. $\geq 18.5)(\mathrm{kg} / \mathrm{m} 2)$ & 0.00974 & \\
\hline & Operability (yes vs. no) & 0.655 & \\
\hline & Smoking history (yes vs. no) & 0.00000735 & \\
\hline & DM (yes vs. no) & 0.854 & \\
\hline & Pathology (confrimed or unknown) & 0.0677 & \\
\hline & Tumor diameter $(<20$ vs. $\geq 20)(\mathrm{mm})$ & 0.347 & \\
\hline & Irradiatiion (gating vs. non-gating) & 0.0752 & \\
\hline Continous variables & & $p$-value & $\rho$ \\
\hline & Age (years) & 0.124 & -0.177 \\
\hline & BMI (kg/m2) & 0.046 & 0.228 \\
\hline & Tumor diameter (mm) & 0.476 & -0.0824 \\
\hline
\end{tabular}


Table 3

The results of univariate analysis for local control rate.

\begin{tabular}{|c|c|c|c|}
\hline & & \multicolumn{2}{|l|}{ Local control rate } \\
\hline & & \multicolumn{2}{|l|}{ univariate } \\
\hline Variables & & Hazard ratio $(95 \% \mathrm{Cl})$ & $\mathrm{p}$ value \\
\hline Age (yraes) & Continuous & $0.9994(0.9132-1.094)$ & 0.9891 \\
\hline Sex & Male vs. female & $1.883(0.2306-15.38)$ & 0.5547 \\
\hline PS & 0 vs. $\geq 1$ & $1.700(0.4053-7.134)$ & 0.4681 \\
\hline BMI $\left(\mathrm{kg} / \mathrm{m}^{2}\right)$ & $18.5<$ vs. $\geq 18.5$ & $2.974(0.7009-12.48)$ & 0.1363 \\
\hline Operability & Yes vs. No & $0.9538(0.1917-4.745)$ & 0.9539 \\
\hline Smoking history & Yes vs. No & $1.413(0.1721-11.61)$ & 0.7474 \\
\hline DM & Yes vs. No & $1.166(0.3765-3.610)$ & 0.7902 \\
\hline Pathology & Confirmed vs. unknown & $0.4003(0.09509-1.685)$ & 0.2219 \\
\hline Tumor diameter (mm) & Continuous & $1.035(0.9517-1.126)$ & 0.4218 \\
\hline Irradiatiion & Gating vs. non-gating & $1.971(0.2397-16.21)$ & 0.5278 \\
\hline Pretreatment $\mathrm{Hb}(\mathrm{g} / \mathrm{dL})$ & Continuous & $0.8074(0.5282-1.234)$ & 0.3230 \\
\hline
\end{tabular}

Table 4

The results of univariate and multivariate analysis for overall survival rate.

\begin{tabular}{|c|c|c|c|c|c|}
\hline & & \multicolumn{4}{|l|}{ Overall survival rate } \\
\hline & & univariate & & multivariate & \\
\hline Variables & & Hazard ratio $(95 \% \mathrm{Cl})$ & $\mathrm{p}$ value & Hazard ratio $(95 \% \mathrm{Cl})$ & $p$ value \\
\hline Age (yraes) & Continuous & $1.032(0.9680-1.100)$ & 0.3371 & & \\
\hline Sex & Male vs. female & $1.743(0.3875-7.843)$ & 0.4689 & & \\
\hline PS & 0 vs. $\geq 1$ & $1.430(0.5281-3.873)$ & 0.4815 & & \\
\hline $\mathrm{BMI}\left(\mathrm{kg} / \mathrm{m}^{2}\right)$ & $18.5<$ vs. $\geq 18.5$ & $4.412(1.515-12.85)$ & 0.006483 & $2.6130(0.8546-7.9900)$ & 0.092100 \\
\hline Operability & Yes vs. No & $0.8752(0.2817-2.719)$ & 0.8177 & & \\
\hline Smoking history & Yes vs. No & $0.5077(0.1569-1.642)$ & 0.2577 & & \\
\hline DM & Yes vs. No & $1.166(0.3765-3.610)$ & 0.7902 & & \\
\hline Pathology & Confirmed vs. unknown & $0.4064(0.1519-1.087)$ & 0.07297 & $0.8924(0.3054-2.6080)$ & 0.835200 \\
\hline Tumor diameter (mm) & Continuous & $1.029(0.9684-1.093)$ & 0.3553 & & \\
\hline Irradiatiion & Gating vs. non-gating & $0.5751(0.1775-1.863)$ & 0.3563 & & \\
\hline Pretreatment $\mathrm{Hb}(\mathrm{g} / \mathrm{dL})$ & Continuous & $0.5647(0.4037-0.7900)$ & 0.0008476 & $0.5897(0.4047-0.8593)$ & 0.005974 \\
\hline
\end{tabular}

\section{Figures}




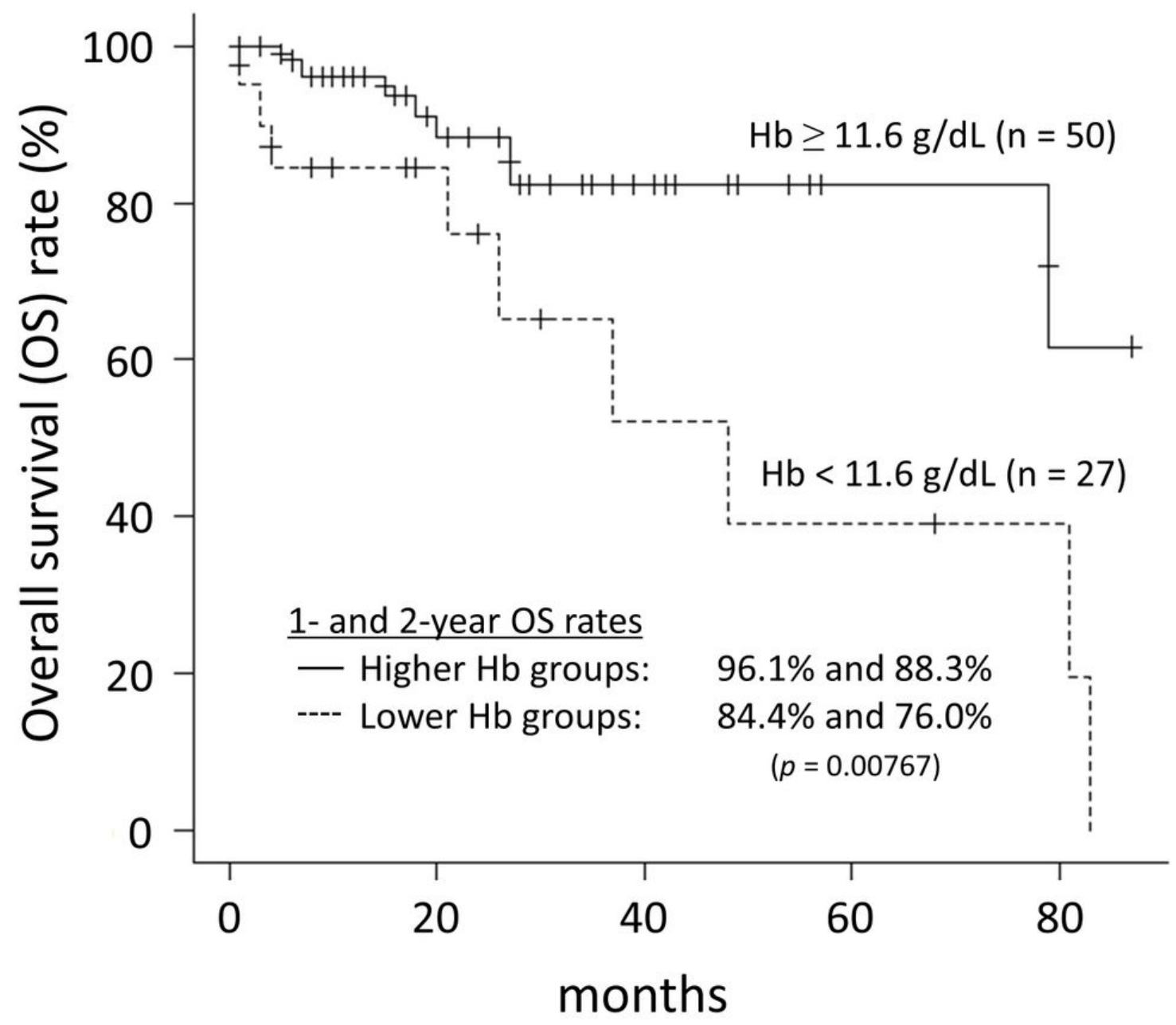

Figure 1

Overall survival rates for high and low hemoglobin groups 